УДК 595.76

DOI 10.18413/2658-3453-2020-2-4-276-281

\title{
ЖЕСТКОКРЫЛЫЕ (INSECTA: COLEOPTERA) ИЗ НОР ЛАСТОЧЕК-БЕРЕГОВУШЕК RIPARIA RIPARIA (LINNAEUS, 1758) (AVES: HIRUNDINIDAE) САРАТОВСКОЙ ОБЛАСТИ
}

\section{THE BEETLES (INSECTA: COLEOPTERA) FROM NESTS OF SAND MARTIN (RIPARIA RIPARIA) (AVES: HIRUNDINIDAE) IN SARATOV REGION}

\author{
А.С. Сажнев ${ }^{1}$, Е.Н. Кондратьев ${ }^{2}$ \\ A.S. Sazhnev ${ }^{1}$, E.N. Kondratiev ${ }^{2}$ \\ ${ }^{1}$ Институт биологии внутренних вод им. И.Д. Папанина Российской академии наука, \\ Россия, 152742, Ярославская область, Борок, 135 \\ ${ }^{2}$ Саратовский государственный университет, \\ Россия, 410012, Саратов, ул. Астраханская, 83 \\ ${ }^{1}$ Papanin Institute for Biology of Inland Waters Russian Academy of Sciences, \\ 135 Borok vill., Yaroslavl Region, 152742, Russia \\ ${ }^{2}$ Saratov State University, \\ 83 Astrakhanskaya St, Saratov, 410012, Russia \\ E-mail: sazh@list.ru; eugene.n.kondratyev@gmail.com
}

\begin{abstract}
Аннотация
В статье приведены материалы (Саратовская область, 2020) по фауне нидикольных жесткокрылых из нор-гнезд береговой ласточки Riparia riparia (Linnaeus, 1758); отмечено 11 видов жуков. Впервые указываются для фауны Саратовской области 4 вида из семейства Staphylinidae: Haploglossa picipennis (Gyllenhal, 1827), Falagrioma thoracica (Stephens, 1832), Leptacinus sulcifrons (Stephens, 1833) и Sepedophilus obtusus (Luze, 1902).

Abstract

The article presents materials (Saratov Region, 2020) on the fauna of the nidicolous beetles from the nestburrows of the sand martin Riparia riparia (Linnaeus, 1758); 11 species of beetles were record. For the first time, 4 species from the Staphylinidae family are indicated for the fauna of the Saratov Region: Haploglossa picipennis (Gyllenhal, 1827), Falagrioma thoracica (Stephens, 1832), Leptacinus sulcifrons (Stephens, 1833), and Sepedophilus obtusus (Luze, 1902).
\end{abstract}

Ключевые слова: фауна, жесткокрылые, норы, гнёзда, нидиколы, новые находки.

Keywords: fauna, beetles, burrows, nests, nidicolous, new records.

\section{Введение}

К настоящему времени накопилось достаточно много работ, посвященных исследованию гнездово-норовой фауны членистоногих, среди которых есть российские и зарубежные публикации, посвященные изучению микробиоценозов нор ласточекбереговушек Riparia riparia (Linnaeus, 1758) [Борисова, 1972, 1978; Якименко и др., 1991; Krištofik et al., 1994; Матросов и др., 2013; Корнеев и др., 2020]. Однако только некоторые из них содержат сведения о жесткокрылых норовых микробиоценозов, тогда как жуки составляют значительную часть таких сообществ, по крайней мере, среди насекомых [Krištofik et al., 1994; Корнеев и др., 2020]. Перечень работ, в которых имеются списки жесткокрылых (на уровне видов и таксонов надвидового ранга) из гнезд-нор береговушек, весьма скромен [Nordberg, 1936; Hicks, 1962; Борисова, 1972, 1978; Крыжановский, Рейхардт, 1976; Šustek, Jurík, 1980; Krištofik et al., 1994; Лундышев, 2012; Lundyshev, Orlov, 2016; Сажнев, Кондратьев, 2019; Корнеев и др., 2020; Сажнев, Матюхин, 2020], а для Саратовской области известны только 3 современные публикации [Сажнев, 
Кондратьев, 2019; Корнеев и др., 2020; Сажнев, Матюхин, 2020], в которых перечислены следующие таксоны Coleoptera: Haploglossa nidicola (Fairmaire, 1852), Platystethus nitens (Sahlberg, 1832), Leptacinus sp., Xantholinus sp. (Staphylinidae); Euspilotus perrisi (Marseul, 1872), Saprinus planiusculus Motschulsky, 1849, Saprinus rugifer (Paykull, 1809) (Histeridae); ?Platytomus variolosus (Kolenati, 1846) (как Pleurophorus) (Scarabaeidae); Dermestes laniarius Illiger, 1801 (Dermestidae); Monotoma sp. (Monotomidae); Anthelephila pedestris (Rossi, 1790), Anthicus antherinus (Linnaeus, 1760) (Anthicidae); Blaps sp. (личинка) (Tenebrionidae) и Spermophagus sericeus (Chrysomelidae). Это говорит о начальном этапе изысканий по теме исследования в регионе.

Настоящая работа - это продолжение начатой инвентаризации нидикольной фауны беспозвоночной норовых микробиоценозов береговой ласточки на территории Саратовской области, цель которой - представить новые данные по жесткокрылым из нор $R$. riparia, которые позволят не только расширить списки видов, но и понять особенности функционирования и формирования сообществ членистоногих, связанных с норовыми микробиоценозами птиц-норников.

\section{Материал и методы исследования}

В основу работы легли данные определения энтомологического материала из гнезд-нор ласточек-береговушек сезона 2020 г. из трех районов Саратовской области: Хвалынский р-н - д. Ивановка (25.06.2020 - обследовано 7 нор, 29.07.2020 - 11 нор), с. Дёмкино (25.06.2020 - обследовано 5 нор, 30.07.2020 - 6 нор), с. Елшанка (26.06.2020 обследовано 4 норы, 30.07.2020 - 8 нор); Лысогорский р-н - д. Симоновка (26.07.2020 обследовано 3 норы), д. Атаевка (26.07.2020 - обследовано 4 норы); Саратовский р-н с. Песчаный Умет (27.07.2020 - обследовано 3 норы).

Гнездовой материал извлекался из нор при их раскапывании и разбирался. Обитатели гнездового субстрата выбирались комбинированным способом - вручную [Высоцкая, 1953] и с помощью электрических термоэклекторов [Фасулати, 1971]. Всего было обследовано 51 гнездо R. riparia. Процент «пустых» проб, где не были обнаружены жесткокрылые, составил $47 \%$.

Гнезда в колонии у д. Ивановка были построены в 2020 г., среди обследованных микроценозов из колоний близ сс. Демкино и Елшанка доминировали прошлогодние (2019) гнезда. В колониях из Лысогорского и Саратовского районов на момент исследований все норы оказались заброшены, что привело к деградации нидикольной фауны (почти все пробы были «пустыми»).

Экогруппы (экологические группы нидиколов) выделены согласно принятым классификациям [Nordberg, 1936]: 1) ботробионты (фолеобии) - типичные обитатели нор и гнезд, которые проходят в них весь жизненный цикл, наиболее специализированные виды; 2) ботрофилы (фолеофилы) - факультативные нидиколы, предпочитающие норы и гнезда, но встречающиеся и в других биотопах; 3) ботроксены (фолеоксены) - эвритопные виды, которые характерны для других местообитаний, но иногда посещают норы и гнезда.

Определение жесткокрылых осуществлено первым автором. Названия таксонов представлены согласно Каталогу жесткокрылых Палеарктики [Catalogue ..., 2007, 2015, 2016]. Материал хранится в коллекции беспозвоночных Института биологии внутренних вод (ИБВВ РАН).

\section{Результаты и их обсуждение}

В результате обработки колеоптерологического материала для нор-гнёзд береговой ласточки района исследования было отмечено 11 видов жуков, 4 из которых оказались новыми для территории Саратовской области.

Основные показатели по видовому составу жесткокрылых 51 обследованной норы $R$. riparia с территории Саратовской области представлены в таблице. 
Таблица

Table

Численность и встречаемость видов жесткокрылых в пробах из гнезд-нор

береговой ласточки Riparia riparia (Linnaeus, 1758), обследованных в 2020 г.

на территории Саратовской области

Numbers of specimens and occurrence of beetle's species in samples from nest-burrows of sand martin Riparia riparia (Linnaeus, 1758) examined in 2020 in the territory of the Saratov Region

\begin{tabular}{|l|c|c|c|}
\hline \multicolumn{1}{|c|}{ Вид } & Численность, экз. & $\begin{array}{c}\text { Индекс } \\
\text { доминирования, \% }\end{array}$ & Встречаемость, \% \\
\hline Haploglossa nidicola (Fairmaire, 1852) & 782 & 97.3 & 45.1 \\
\hline Haploglossa picipennis (Gyllenhal, 1827) & 3 & 0.4 & 3.9 \\
\hline Falagrioma thoracica (Stephens, 1832) & 1 & 0.1 & 2.0 \\
\hline Leptacinus sulcifrons (Stephens, 1833) & 3 & 0.4 & 2.0 \\
\hline Sepedophilus obtusus (Luze, 1902) & 1 & 0.1 & 2.0 \\
\hline Saprinus rugifer (Paykul, 1809) & 8 & 1.0 & 2.0 \\
\hline Pleurophorus caesus (Creutzer, 1796) & 1 & 0.1 & 2.0 \\
\hline Agrilus hyperici (Creutzer, 1799) & 1 & 0.1 & 2.0 \\
\hline Lampyris noctiluca (Linnaeus, 1767) & 1 & 0.1 & 2.0 \\
\hline Sericoderus lateralis (Gyllenhal, 1827) & 1 & 0.1 & 3.9 \\
\hline Corticaria sp. & 2 & 0.3 & \\
\hline
\end{tabular}

Новые находки жесткокрылых из семейства Staphylinidae для фауны региона приведены полностью с описанием этикеток для каждого экземпляра и краткими экологическими характеристиками видов.

1. Haploglossa picipennis (Gyllenhal, 1827)

Материал: Хвалынский р-н, окр. с. Елшанка, берег пруда на р. Елшанка, 26.06.2020 (3 экз.) Е.Н. Кондратьев leg.

Нидикольный вид, ботробионт, чаще встречается в гнездах хищных и врановых птиц, приводится для нор береговушек из Белоруссии [Lundyshev, Orlov, 2016]. Впервые указывается для Саратовской области. Для России был известен для севера и центра Европейской части [Catalogue ..., 2015]. В отличие от близкого вида Haploglossa nidicola в норовых микробиоценозах R. riparia встречается значительно реже. Среди представителей этого рода для гнезд-нор береговой ласточки отмечен еще один вид Haploglossa villosula (Stephens, 1832) [Krištofik et al., 1994; Lundyshev, Orlov, 2016], возможный для Саратовской области, но пока что не известный из региона.

2. Falagrioma thoracica (Stephens, 1832)

Материал: Хвалынский р-н, окр. с. Елшанка, берег пруда на р. Елшанка, 26.06.2020 (3 экз.) Е.Н. Кондратьев leg.

Рипасапробионт [Гореславец, 2014], отмечается по берегам водных объектов и во влажной подстилке. Европейско-средиземноморский вид [Catalogue ..., 2015]. Для Саратовской области ранее не был известен. Нами рассматривается в качестве ботроксена, проникающего в гнезда из прилегающих биотопов, в частности с берега водоема, однако, при дальнейшем изучении нидикольных сообществ, статус вида может поменяться.

3. Leptacinus sulcifrons (Stephens, 1833)

Материал: Хвалынский р-н, окр. д. Ивановка, берег р. Волга, 29.07.2020 (2 экз.) Е.Н. Кондратьев leg.; там же, окр. с. Елшанка, берег пруда на р. Елшанка, 30.07.2020 (1 экз.) Е.Н. Кондратьев leg.

Ботрофил, обитает в разложившихся растительных останках, навозе, на открытых пространствах, включая берега водных объектов. Западнопалеарктический вид [Catalogue ..., 2015]. Для Саратовской области приводится впервые. Из этого рода в гнездах R. riparia отмечены Leptacinus batychrus (Gyllenhal, 1827) и L. pusillus (Stephens, 1833) [Krištofik et al., 1994], видимо, близкие по экологии. 


\section{Sepedophilus obtusus (Luze, 1902)}

Материал: Хвалынский р-н, окр. д. Ивановка, берег р. Волга, 25.06.2020 (1 экз.) Е.Н. Кондратьев leg.

Нами расценивается как ботроксен. Обитает в подстилке, как гостевой элемент - по берегам водных объектов [Гореславец, 2014]. Европейско-средиземноморский вид [Catalogue ..., 2015]. Для Саратовской области приводится впервые.

Норы ласточек-береговушек представляют собой субтерральный сложный многолетний нидоценоз [Сажнев, Матюхин, 2020], в большинстве из них встречены облигатные нидиколы (ботробионты) - стафилиниды рода Haploglossa (встречаемость 42.9-45.1\% [Сажнев, Кондратьев, 2019]), а также Euspilotus perrisi (единичная находка [Сажнев и др., 2018]) и Saprinus rugifer (встречаемость 9.5-11.4 \% [Сажнев, Кондратьев, 2019]). В целом же сообщества жесткокрылых исследованных норовых микробиоценозов ласточек-береговушек имеют ботрофильный облик (50 \% от всех видов), 13.6 \% в фауне занимают ботрофилы, а $36.4 \%$ - ботроксены (так, к случайным элементам можно отнести Agrilus hyperici, Lampyris noctiluca). Поэтому стоит учитывать, что последняя группа представлена в сборах единичными особями, тогда как характерные для норовых сообществ облигатные нидиколы по численности составляют 98.3 \% (см. таблицу).

Согласно литературным [Šustek, Jurík, 1980; Krištofik et al., 1994; Lundyshev, Orlov, 2016] и собственным [Сажнев и др., 2018; Сажнев, Кондратьев, 2019] данным, наиболее массовые виды в гнездах-норах R. riparia среди жесткокрылых - это Haploglossa nidicola и Saprinus rugifer. Впервые для нидоценозов ласточек-береговушек отмечены Falagrioma thoracica, Leptacinus sulcifrons, Sepedophilus obtusus, Pleurophorus caesus, Sericoderus lateralis, еще два вида - Agrilus hyperici и Lampyris noctiluca - ранее не отмечались для исследуемых гнездовых сообществ, однако, являются случайными элементами из сопутствующих биотопов и не имеют консортивных связей с эдификатором.

\section{Благодарности}

Часть работы А.С. Сажнева проведена в рамках выполнения государственного задания Министерства науки и высшего образования РФ (ААAA-A18-118012690105-0). Авторы выражают признательность за помощь в проведении экспедиционных работ В.В. Аникину (СГУ, Саратов).

\section{Список литературы}

1. Борисова В.И. 1972. Итоги изучения экологии гнездово-норовых паразитов птиц ТАССР. Паразитология, 6 (5): 457-464.

2. Борисова В.Н. 1978. К структуре гнездо-норовых ценозов ласточек. Паразитология, $12(5): 377-382$.

3. Высоцкая С.О. 1953. Методы сбора обитателей гнезд грызунов. М., Изд-во АН СССР, 47 с.

4. Гореславец И.Н. 2014. Стафилиниды (Coleoptera, Staphylinidae) - обитатели берегов пресноводных водоемов Самарской области. Самарская Лука: проблемы региональной $и$ глобальной экологии, 23 (2): 165-177.

5. Корнеев М.Г., Поршаков А.М., Яковлев С.А., Матросов А.Н., Сажнев А.С. 2020. Членистоногие - обитатели нор береговой ласточки Riparia riparia (Linnaeus, 1758) (Aves: Hirundinidae) на территории Саратовской области. Известия Саратовского университета. Новая серия. Сер. Химия. Биология. Экология, 20(2): 189-199. DOI https://doi.org/10.18500/1816-97752020-20-2-189-199.

6. Крыжановский О.Л., Рейхардт А.Н. 1976. Фауна СССР. Жесткокрылые. Т. 5. Вып. 4. Жуки надсемейства Histeroidea (семейства Sphaeritidae, Histeridae, Synteliidae). M.-Л., Наука, 435 с.

7. Лундышев Д.С. 2012. Некробионтные жесткокрылые рода Saprinus (Coleoptera, Histeridae) юга Беларуси. Веснік Брэсикага ууніверсітэта. Серыя 5. Хімія. Біялогія. Навукі аб зямлі, 2: 34-40. 
8. Матросов А.Н., Чекашов В.Н., Поршаков А.М., Яковлев С.А., Шилов М.М., Кузнецов А.А., Захаров К.С., Князева Т.В., Мокроусова Т.В., Толоконникова С.И., Удовиков А.И., Красовская Т.Ю., Шарова И.А., Кресова У.А., Кедрова О.В., Попов Н.В., Щербакова С.А., Кутырев В.В. 2013. Условия циркуляции вируса и предпосылки формирования природных очагов лихорадки Западного Нила в Саратовской области. Проблемы особо опасных инфекиий, (3): 17-22.

9. Сажнев А.С., Кондратьев Е.Н. 2019. Материалы по фауне жесткокрылых-нидиколов (Insecta: Coleoptera) из нор ласточек-береговушек Riparia riparia (Linnaeus, 1758) (Aves: Hirundinidae) Саратовской области. Полевой журнал биолога, 1 (4):193-197. DOI 10.18413/26583453-2019-1-4-193-197.

10. Сажнев А.С., Матюхин А.В. 2020. Материалы к фауне жесткокрылых (Insecta: Coleoptera) нидоценозов птиц. Полевой журнал биолога, 2 (1): 14-23. DOI 10.18413/2658-34532020-2-14-23.

11. Сажнев А.С., Поршаков А.М., Корнеев М.Г. 2018. Новый для фауны Саратовской области вид Histeridae (Insecta: Coleoptera) из нор Riparia riparia (Linnaeus, 1758) (Aves: Hirundinidae). Энтомологические и паразитологические исследования в Поволжье, 15: 107-108.

12. Фасулати К.К. 1971. Полевое изучение наземных беспозвоночных. М., Высшая школа, 424 с.

13. Якименко В.В., Богданов И.И., Тагильцев А.А. 1991. Членистоногие убежищного комплекса в колониальных поселениях береговой ласточки на территории Западной Сибири и Восточного Казахстана. Паразитология, 25 (1): 39-47.

14. Catalogue of Palaearctic Coleoptera. 2007. Vol. 4. Elateroidea - Derodontoidea Bostrichoidea - Lymexyloidea - Cleroidea - Cucujoidea. I. Löbl, A. Smetana (eds.). Stenstrup, Apollo Books, $935 \mathrm{p}$.

15. Catalogue of Palaearctic Coleoptera. 2015. Vol. 2. Revised and updated version. Hydrophiloidea - Staphylinoidea. I. Löbl, D. Löbl (eds.). Leiden-Boston, Brill., 1702 p.

16. Catalogue of Palaearctic Coleoptera. 2016. Vol. 3. Scarabaeoidea, Scirtoidea, Dascilloidea, Buprestoidea, Byrrhoidea. Eds. I. Löbl, A. Smetana. Stenstrup: Brill. 984 p.

17. Hicks E.A. 1962. Check-list and bibliography on the occurrence of insects in birds' nests. Supplement I. Iowa State Journal of Science, 36: 233-348.

18. Krištofík J., Šustek S., Gajdoš P. 1994. Arthropods in nests of the Sand Martin (Riparia riparia Linnaeus, 1758) in South Slovakia. Biologia, Bratislava, 49(5): 683-690.

19. Lundyshev D.S., Orlov I.A. 2016. Beetles of the genus Haploglossa Kraatz, 1856, and Atheta Thomson, 1858, (Coleoptera, Staphylinidae) - inhabitants of bird nests in Belarus. Вестник БарГУ. Сер. Биологические науки (общая биология). Сельскохозяйственные науки (агрономия), 4: 58-62.

20. Nordberg S. 1936. Biologisch-ökologische Untersuchungen uber die Vogelnidicolen. Acta zoologica Fennica, 21: 1-168.

21. Šustek Z., Jurík M. 1980. The Coleoptera from the nests of Riparia riparia in Czechoslovakia. Věstník Československé společnosti zoologické, 44: 286-292.

\section{Reference}

1. Borisova V.I. 1972. On ecology of burrow-nest parasites of birds from Tataria. Parasitology, 6 (5): 457-464. (in Russian)

2. Borisova V.I. 1978. On the structure of nest-burrow coenoses of martins. Parasitology, 12 (5): 377-382. (in Russian)

3. Vysotskaya S.O. 1953. Metody sbora obitateley gnezd gryzunov [Collection methods of rodent nest inhabitants]. Moscow, Izd-vo AN USSR, 47 p.

4. Goreslavets I.N. 2014. Rove (Coleoptera, Staphylinidae) Inhabitants shores freshwater waters Samara region. Samarskaya Luka: problems of regional and global ecology, 23 (2): 165-177. (in Russian)

5. Korneev M.G., Porshakov A.M., Yakovlev S.A., Matrosov A.N., Sazhnev A.S. 2020. Arthropods - Inhabitants of Burrows of the Sand Martin Riparia riparia (Linnaeus, 1758) (Aves: Hirundinidae) on the Territory of the Saratov Province. Izvestiya of Saratov University. New Series. Series: Chemistry. Biology. Ecology, 20(2): 189-199. DOI https://doi.org/10.18500/1816-9775-2020-202-189-199. (in Russian)

6. Kryzhanovsky O.L., Reichardt A.N. 1976. Fauna SSSR. Zhestkokrylyye. T. 5. Vyp. 4. Zhuki nadsemeystva Histeroidea (semeystva Sphaeritidae, Histeridae, Synteliidae). [Fauna of the USSR. 
Coleoptera. T. 5. Vol. 4. Beetles of the superfamily Histeroidea (families Sphaeritidae, Histeridae, Synteliidae).]. Moscow-Leningrad, Nauka, $435 \mathrm{p}$.

7. Lundyshev D.S. 2012. Necrobiotic Beetles of Saprinus Genus (Coleoptera, Histeridae) in the South of Belarus. Bulletin of Brest University. Series 5. Chemistry. Biology. Earth sciences, 2: 34-40. (in Russian)

8. Matrosov A.N., Chekashov V.N., Porshakov A.M., Yakovlev S.A., Shilov M.M., Kuznetsov A.A., Zakharov K.S., Knyazeva T.V., Mokrousova T.V., Tolokonnikova S.L., Udovikov A.I., Krasovskaya T.Yu., Sharova I.N., Kresova U.A., Kedrova O.V., Popov N.V., Shcherbakova S.A., Kutyrev V.V. 2013. Conditions for Virus Circulation and Premises for Natural West Nile Fever Foci Formation in the Territory of the Saratov Region. Problemy Osobo Opasnykh Infektsii [Problems of Particularly Dangerous Infections], (3): 17-22. (in Russian)

9. Sazhnev A.S., Kondratiev E.N. 2019. Data on the Fauna of Beetles-Nidicoles (Insecta: Coleoptera) from Nests of Sand Martin (Riparia riparia) (Aves: Hirundinidae) of Saratov Province. Field Biologist Journal, 1 (4):193-197. DOI 10.18413/2658-3453-2019-1-4-193-197. (in Russian)

10. Sazhnev A.S., Matyukhin A.V. 2020. Data to the Fauna of Beetles (Insecta: Coleoptera) of Bird's Nidocenoses. Field Biologist Journal, 2(1): 14-23. DOI 10.18413/2658-3453-2020-2-14-23. (in Russian)

11. Sazhnev A.S., Porshakov A.M., Korneev M.G. 2018. New species of Histeridae (Insecta: Coleoptera) from burrows of Riparia riparia (Linnaeus, 1758) (Aves: Hirundinidae) for the fauna of Saratov province. Entomological and Parasitological Investigations in Povolzh'e Region, (15): 107-108. (in Russian)

12. Fasulati K.K. 1971. Polevoe izuchenie nazemnykh bespozvonochnykh [Field study of terrestrial invertebrates]. Moscow, Vysshaya shkola, $424 \mathrm{p}$.

13. Jakimenko V.V., Bogdanov I.I., Tagiltsev A.A. 1991. Arthropods of the nest complex in colonies of sand martin in west Siberia and South Kazakhstan. Parasitology, 25 (1): 39-47. (in Russian)

14. Catalogue of Palaearctic Coleoptera. 2007. Vol. 4. Elateroidea - Derodontoidea Bostrichoidea - Lymexyloidea - Cleroidea - Cucujoidea. I. Löbl, A. Smetana (eds.). Stenstrup, Apollo Books, $935 \mathrm{p}$.

15. Catalogue of Palaearctic Coleoptera. 2015. Vol. 2. Revised and updated version. Hydrophiloidea - Staphylinoidea. I. Löbl, D. Löbl (eds.). Leiden-Boston, Brill., 1702 p.

16. Catalogue of Palaearctic Coleoptera. 2016. Vol. 3. Scarabaeoidea, Scirtoidea, Dascilloidea, Buprestoidea, Byrrhoidea. Eds. I. Löbl, A. Smetana. Stenstrup: Brill. 984 p.

17. Hicks E.A. 1962. Check-list and bibliography on the occurrence of insects in birds' nests. Supplement I. Iowa State Journal of Science, 36: 233-348.

18. Krištofík J., Šustek S., Gajdoš P. 1994. Arthropods in nests of the Sand Martin (Riparia riparia Linnaeus, 1758) in South Slovakia. Biologia, Bratislava, 49(5): 683-690.

19. Lundyshev D.S., Orlov I.A. 2016. Beetles of the genus Haploglossa Kraatz, 1856, and Atheta Thomson, 1858, (Coleoptera, Staphylinidae) - inhabitants of bird nests in Belarus. Вестник БарГУ. Сер. Биологические науки (общая биология). Сельскохозяйственные науки (агрономия), 4: 58-62.

20. Nordberg S. 1936. Biologisch-ökologische Untersuchungen uber die Vogelnidicolen. Acta zoologica Fennica, 21: 1-168.

21. Šustek Z., Jurík M. 1980. The Coleoptera from the nests of Riparia riparia in Czechoslovakia. Věstník Československé společnosti zoologické, 44: 286-292.

Поступила в редакичию 10.10.2020

\section{Ссылка для цитирования статьи For citation}

Сажнев А.С., Кондратьев Е.Н. 2020. Жесткокрылые (Insecta: Coleoptera) из нор ласточекбереговушек Riparia riparia (Linnaeus, 1758) (Aves: Hirundinidae) Саратовской области. Полевой журнал биолога, 2 (4): 276-281. DOI 10.18413/2658-3453-2020-2-4-276-281

Sazhnev A.S., Kondratiev E.N. 2020. The Beetles (Insecta: Coleoptera) from Nests of Sand Martin (Riparia riparia) (Aves: Hirundinidae) in Saratov Region. Field Biologist Journal, 2 (4): 276-281. DOI 10.18413/2658-3453-2020-2-4-276-281 (in Russian) 